The bottleneck in the application of indirect calorimetry is still the need for laborious and skilful gas analysis. It is this bottleneck that is now under attack in this laboratory. If the attack is successful, the results will be, first a robust oxygen analyser for laboratory use, with a very short response time and small dead space, and later an adaptation of it sufficiently light to be carried by the subject. This in combination with a flow meter will produce an answer directly in terms of oxygen consumption.

\title{
REFERENCES
}

Douglas, C. G. (191 1). F. Physiol. 42, xvii.

Kofrányi, E. \& Michaelis, H. F. (I940). Arbeitsphysiologie, II, I48.

\section{Energy expenditure in relation to nutrition}

By O. G. Edholm, Division of Human Physiology, National Institute for Medical Research, Medical Research Council, c/o Medical Research Council Laboratories, Holly Hill, Hampstead, London, N.W.3

The two sides of the energy balance have had uneven treatment in the past. Calorie intake has been very thoroughly investigated, and the techniques of dietary surveys have been brought to a high standard of accuracy. Tables giving the calorie values of nearly all foods and drinks are available, so it is not surprising that there is such a volume of information available on calorie consumption.

There is also a very considerable literature on the energy expenditure on particular activities, but less information on total energy expenditure. The methods which can be employed have been described by Douglas (I956) and Wolff (1956). Up to the present, direct calorimetry is the only method by which continuous recording of energy expenditure for a long time can be obtained.

The limitations of direct calorimetry are the expense of the construction of a suitable chamber, the restrictions imposed on the activity of the subject, and the fact that such investigations must be made in the laboratory. Indirect calorimetry can be used in the field but continuous recording of activity is difficult, and in practice energy expenditure is measured by recording for brief intervals and applying the values obtained for the whole period of time occupied by that activity.

Computation is therefore the basis for calculating energy expenditure. The information necessary is:

(I) A list of the activities of the day and the time spent on each.

(2) The energy expenditure on each of these activities. The simplest type of calculation would be one which has been frequently used, i.e. division of the day into $8 \mathrm{~h}$ sleep, $8 \mathrm{~h}$ work, and $8 \mathrm{~h}$ recreation. The calorie expenditure during sleep can be taken as equal to the basal metabolic rate. The $8 \mathrm{~h}$ off work can be assumed to be approximately $3 \times$ B.M.R., leaving the energy expenditure during work as the main variable, and studies outside the laboratory have therefore been mainly concerned with this variable. 
Many published values can be found for the calorie cost of different occupations, and it has been possible to compute the total energy expenditure of, e.g., coal miners, bricklayers, clerks.

Progression from this stage of knowledge, with its obvious limitations, to the stage of complete measurement is long and laborious. A time-and-motion study is necessary to break down the activities of the day into usable terms. A diary can be kept by the subject, or an observer can record the duration and type of activity; a combination of the two methods is the most useful. Such a combination has been employed in recent surveys of energy expenditure in the field, e.g. by Garry, Passmore, Warnock \& Durnin (1955), Widdowson, Edholm \& McCance (1954) and Edholm, Fletcher, Widdowson \& McCance (1955).

Where activity is homogeneous, i.e. a group of subjects is engaged on the same task, one observer is sufficient. Otherwise one observer per subject is required for such activities where it is not practical for the subject to record details. The subject must be capable of recording his or her activity in a simple code, without interfering with ordinary life. This demands a considerable degree of co-operation from the subject.

The information obtained from the time-and-activity study is next codified, so the total length of time in any one day spent on a particular activity is tabulated.

The energy spent on each of these activities can be obtained by direct measurement on the individual subject, and the total energy expenditure is computed. In practice, a sample of each activity can be measured as it occurs, or can be reproduced by the subject when convenient. In studies on military cadets by Widdowson et al. (1954) and Edholm et al. (1955), it was not feasible to make such measurements during drill parades, so the subjects performed a period of drill at a time when measurements could then be made without interference. It was assumed that the results could be applied to other drill periods. Recourse can also be made to published figures for the energy expenditure of particular activities, and these values may be used in the final calculation. Neither of these methods is entirely satisfactory. Even for simple activities such as sitting or standing there can be considerable variation between subjects even when allowance is made for surface area and weight (Edholm \& Fletcher, 1955), so an average value for the energy cost of sitting may be misleading when applied to a particular individual. More complex activities may show wider individual variation. Even when measurements are made on the individual on one occasion the results obtained are unlikely to be precisely the same as on a subsequent occasion. Drill parades have been mentioned: time-and-motion studies showed that these were frequently not identical. Furthermore, as the cadets were being trained their performance improved, hence their energy expenditure could also have changed.

If the average energy expenditure of a group of individuals is required, the objections mentioned above are probably not so important, as errors are likely to cancel each other.

The technical difficulties of extending indirect calorimetry to cover a longer period of time are considerable. In general, the Douglas bag (Douglas, I9I I) or the 
Kofrányi-Michaelis calorimeter (Kofrányi \& Michaelis, I940) or both are used. Except for very low ventilation rates, measurements can only last for $3^{- \text {ro }}$ min, as the Douglas bag or the sample bag on the Kofranyi-Michaelis apparatus will be full.

An attempt is now being made to measure ventilation volume and oxygen consumption for as long as possible during the day, using the integrated motor pneumotachograph (IMP) (Wolff, 1956). The instrument has been worn by subjects for a total period of 8-1o h/day for a week at a time, without apparent discomfort or interference with activity, including all the strenuous work involved in an army recruit's training, such as gymnastics and field exercises.

The results obtained from the measurement of energy expenditure cannot replace the information obtained in nutritional surveys. A knowledge of the total energy expenditure is of no assistance in assessing the nutritional qualities of the diet as regards vitamin or mineral requirements or the balance between protein, fat and carbohydrate. It would be an error to conceive of the measurement of energy expenditure as replacing a dietary survey, except for a figure of total calorie intake needed to balance output.

Furthermore, an energy-expenditure survey requires a large team of workers, is laborious, and therefore expensive. Approximately three times as many individuals are needed for energy-expenditure teams as for a dietary survey. Provided that growth has ceased and weight changes are insignificant, then intake and output must balance, so the total food intake over a period will equal the total energy expenditure.

What is the justification for carrying out an energy-expenditure survey at all? First of all it shows how the calories are used. The proportion of the total calories expended during the working occupation of the individual compared with the rest of the day can be determined. The time-and-motion study shows the activity pattern, i.e. the total time spent lying, sitting, standing, walking and in other ways, and the proportion of energy used in these activities. There is still little information available on the way in which individuals in different occupations spend their day.

Secondly, a comparison can be made between the daily intake and expenditure. Results obtained so far indicate that a daily calorie balance may be the exception rather than the rule. In the studies on military cadets (Edholm et al. 1955) there was no evident correlation between daily intake and output. The best correlation obtained was between daily expenditure and the intake 2 days later. If this finding is confirmed, it will show the need to investigate the mechanism of appetite. The results all suggest that when energy expenditure is unusually high for the individual, then the food intake during that period will be lower than average. Possibly one is too tired to eat.

Studies of the energy expenditure and food intake of the population of an African farming village (Fox, I953), extended over a year, have shown that calorie imbalance can be prolonged. A time of food shortage coincided with the most energetic period when the ground was being prepared for the new crop. This was succeeded, when the crop had been harvested, by a period when food intake exceeded energy 
expenditure. Calorie balance in this instance was achieved, not on a daily or monthly basis, but only over a period of a year.

These results indicate the need for further studies, combining energy-expenditure measurements with food-intake records, on people following different occupations. The two sides of the inquiry illumine each other: the one does not replace the other.

\section{REFERENCES}

Douglas, C. G. (191 I). भ. Physiol. 42, xvii.

Douglas, C. G. (1956). Proc. Nutr. Soc. 15, 72.

Edholm, O. G. \& Fletcher, J. G. (1955). F. Physiol. 128, I 8 P.

Edholm, O. G., Fletcher, J. G., Widdowson, E. M. \& McCance, R. A. (1955). Brit. F. Nutr. 9, 286.

Fox, R. H. (1953). A study of energy expenditure of Africans engaged in various rural activities. Thesis submitted for the Ph.D. Degree, University of London.

Garry, R. C., Passmore, R., Warnock, G. M. \& Durnin, J. V. G. A. (1955). Spec. Rep. Ser. med. Res. Coun., Lond., no. 289.

Kofrányi, E. \& Michaelis, H. F. (r940). Arbeitsphysiologie, 11, 148.

Widdowson, E. M., Edholm, O. G. \& McCance, R. A. (1954). Brit. F. Nutr. 8, 147.

Wolff, H. S. (1956). Proc. Nutr. Soc. 15, 77.

\section{Daily energy expenditure by man}

\section{By R. Passmore, Department of Physiology, University of Edinburgh}

'The greatest mystery about a human being is not his reaction to sex or praise, but the manner in which he contrives to put in twenty four hours a day. It is this which puzzles the longshoreman about the clerk, the Londoner about the Bushman. It was this that puzzled Carol in regard to the married Vida.' (Sinclair Lewis in Main Street).

In western Europe, in North America, in Australia and in New Zealand the daily energy expenditure of large numbers of the population is less than the energy derived from their food. In consequence the people become fat. In Asia, in Africa and in many countries in Latin America the food supply is insufficient to meet the energy needs of daily life. As a result many persons in these countries are thin: they also become lethargic. There is a consensus of medical opinion that such calorie imbalances, the positive and the negative, are both detrimental to health and working efficiency. Our civilizations are failing either to disperse people throughout the world to the agricultural sources of available food or, alternatively, to distribute foods by the mechanism of international trade according to the physiological needs of the population. The latest data from FAO (1955) presented in Table $\mathrm{I}$ indicate that the disproportions in the distribution of food are increasing rather than diminishing. Whatever the physiological yardstick of calorie needs, many persons in North America and western Europe eat beyond the mark and vast numbers in the Far East and Latin America can have no chance to obtain a sufficiency of foods for their needs.

Hitherto estimates of calorie needs have been based predominantly on the results of measurements of calorie intake determined by dietary surveys. This procedure 